\title{
WHAT IS THE REAL EFFECT OF SCHOOLING ON ECONOMIC GROWTH?
}

\section{Rudolf Kubík*}

\begin{abstract}
:
This paper examines the effect of schooling on economic growth. It tests the link between schooling and economic growth using the system GMM estimation for a panel of 86 countries in the years 1960-2005. Affirming the results of the previous literature the positive impact of schooling on growth has been confirmed. The paper presents two main findings. First, additional year of schooling contributes positively to per capita output growth. Secondly, high percentage share of population with no formal education results in economic growth slowdown.
\end{abstract}

Keywords: education, growth, human capital, GMM estimation.

JEL Classification: 011, 121, C33

\section{Introduction}

The impact of the human capital on economic growth has been repeatedly tested in several empirical papers since the 1990s. Significant positive effect of schooling as a key component of the human capital on economic growth has been confirmed but the level of the impact has not been generally acknowledged yet. Particularly the intensity of the relationship and the potential impact of the human capital on growth is still a subject of research.

As the education is in many countries considerably budgeted from the public accounts thus the topic is important not only for the growth accounting but for the public and educational policy-makers as well.

Strong incentive to attach macroeconomists' focus to the human capital topic gave already Nelson and Phelps in 1966, who comment that education generates capacity of population to innovate and adopt new technologies. Later on, the "new growth" literature represented mainly by Lucas (1988) and Romer (1990) started to examine the impact of the human capital on the sustainable long-term economic growth and concluded that the

* Department of Public Finance, University of Economics, Prague, Czech Republic (r.kubik@centrum.cz). This paper is part of the Project IGA VŠE No. F1/30/2010 "Influence of Tax and Nontax Tools on Micro and Macroeconomic Effectiveness". 
impact of the physical capital on growth had been overstated due to the disregard of the human capital in the growth models.

Recent investigation of Barro and Lee (2010) concludes that the world income would increase by $5.5 \%-12.1 \%$ for every additional year of schooling which is very close to the previous results of Topel (1999) or Soto (2008) and is also consistent with the Mincerian return-to-schooling at the $10 \%$ level. On the other hand, there are several authors who state that the influence of the human capital is being for many reasons overstated as well.

For example Nehru, Svanson and Dubey (1993), Benhabib and Spiegel (1994), Hall and Jones (1999) conclude that not only the schooling but also other important factors such as social infrastructure or new technologies adoption have to be concerned in the economic growth models in order to get plausible estimates. Fuente and Domenech (2000) contested the impact of the human capital on growth due to reverse causality. They conclude that the positive correlation invoke significant positive bias of the coefficients.

Other frequently examined reasons for questioning the real impact of the human capital on growth have one common denominator: poor data quality. Human capital itself is basically very difficult variable to measure and quantify. Usually, the approximation is done by the already mentioned average years of schooling, first introduced by Psacharopoulos and Ariagada in their work The Educational Attainment of the Labour Force in 1986. But the quality of the primary data for the average years of education can notably vary in the cross-country time series and consequently influence the results $(e . g$. see Kruger and Lindhal, 2001 or Cohen and Soto, 2007). Moreover, there is very poor methodological consistency for the average years of schooling calculations among the countries and within the time.

This altogether supports the Pritchett's finding that schooling has no positive effect on the growth rate of economic output per worker. The main reasons for this finding are also formulated in the so called Pritchett hypothesis. Prichett (2001) also comments that the approximation by the average years of schooling have an unrealistic assumption that every additional year of schooling brings constant additional amount of the human capital. Moreover, this approximation neither reflects different effect and importance of the different levels of education - primary, secondary and tertiary level, nor the share of uneducated population.

This criticism is being addressed in this paper as well and in order to reach plausible validation of the human capital effect additional variables are incorporated and tested in the growth model.

The importance to consider the impact of the different levels of education is accented in the work of Barro and Lee (2010). They tested separately the average years of schooling for primary, secondary and tertiary level of education and concluded that this invokes important variations of the results. Surprisingly, according to their findings, the average years of the primary level of education have negative effect on the economic growth. On the other hand, the average years of schooling for secondary and tertiary level affect the economic growth in a positive way.

Describing the real effect of the human capital on economic growth is a more difficult discipline than it has been expected. Soto (2008) incorporates also the quality of the human capital into the growth model. He concluded that the average years of schooling variable is statistically significant determinant of the economic growth only in countries with high quality of educational system and insignificant in countries with low quality of schooling. 
The human capital quality issue has been developing intensively within the last years. For instance Hanushek and Woessmann (2008) reported that the quality of the human capital can be even more important growth effecting factor than the school enrolment. Prichett (2001) comments that not reflecting the quality of the human capital can considerably overestimate its impact on the growth.

This paper aims to further examine the link between the human capital and the economic growth and try to get some clear answers on what is the real effect of the schooling and how to approximate its "value" correctly. Coming out from earlier empirical research it combines different econometric approaches, includes new proxies of the human capital and accounts also for the quality of schooling. This altogether should bring unbiased and more plausible and accurate estimates. These are introduced basically in three parts.

First, following the earlier research it tests whether there is positive effect of the human capital approximated by the average years of education on economic output. This forms benchmark estimation for subsequent testing and additionally the paper enables to compare results from different econometric methods in order to test estimates' consistency.

Secondly, it further develops the previous research done mainly by Soto (2008) and tries to answer how the estimates change once the quality of the human capital is incorporated and reflected in the growth model. As Prichett (2001) or Hanushek and Woessmann (2008) indicated this should bring more accurate estimates of the human capital effect on economic growth.

The third part of the paper follows the significant criticism of the usually applied approximation of the human capital by the average years of schooling, and applies shares of population with different level of education as a proxy for the human capital instead. Different impact of the primary, secondary and tertiary level of education on economic growth is being examined. Moreover, as assumed, there could be significant negative relationship between the share of uneducated population and economic growth, which is tested as well.

The paper is organised as follows. In the next two parts the source of data and econometric model and methods are described. The empirical section is divided into three parts mapping the three main objectives and covering the main results.

\section{Panel Data, Sources and Basic Data Overview}

The panel dataset covers 92 countries in the years 1960-2005 at 5-year interval. Data have been obtained from the following sources. First, the schooling data (both the percentage share of population with no education and the average years of schooling) was extracted from the updated Barro and Lee panel data set from 2010. ${ }^{1}$ Secondly, economic output and physical capital per capita data originates from the Penn World Table (PWT Version 6.3). The economic output is measured as the real GDP per capita in international dollars and the same approximation is used in all following tests.

Following Hall and Jones (1999) the stock of physical capital is estimated by the perpetual inventory method. Based on the perpetual inventory method following equation for the physical capital is estimated

1 Full data set available at www.barrolee.com. 


$$
K_{i, t}=I_{i, t}+K_{i, t-1}(1-\delta)
$$

where $I_{i . t}$ is the investment flow in country $i$ and year $t$ and $\delta$ is the depreciation rate. $K_{i . t}$ denotes the stock of physical capital in country $i$ and year $t$. According to Caseli (2005) the investment data is extracted from PWT 6.3 as real aggregate investment in PPP. As in Bernanke and Gurkaynak (2001) the depreciation rate is set to 0.06. An initial value of the physical capital stock is generated by

$$
K_{i, 0}=I_{i, 1} /\left(g_{i, 1}+\delta\right)
$$

where $g$ is the average geometric growth rate for the investment flow in country $i$ within 1960-1970. $K$ and $I$ denote again the stock of physical capital and investment flow.

Following figure introduces the main variables in the panel and its development in the years 1960-2005.

\section{Figure 1 | Main Variables in 1960-2005 (averages, 92 countries)}

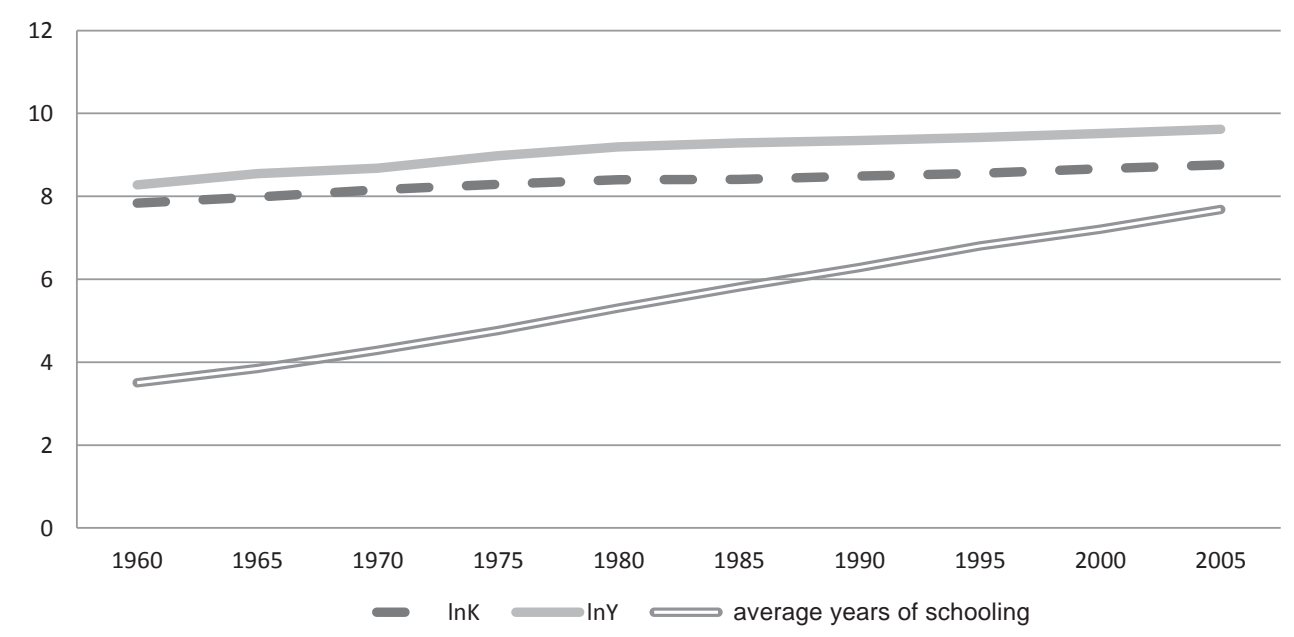

Notes: InK... log of physical capital per capita, InY... log of economic output (measured as real GDP per capita in international dollars), y axis represents two units - for average years of schooling is the unit "years", for InY and InK is the unit logarithm of absolute values of $\mathrm{Y}$ (economic output) and K (stock of physical capital) Source: Barro and Lee (2010), PWT 6.3, own calculations

The Figure 1 shows there is notable and constant increase in all variables over the depicted time-frame and might there be some relationship. Indeed, we have to analyse the data in detail to draw some relevant conclusions. Interestingly, for example countries of Sub-Sahar Africa report triple higher average years of schooling in 2005 than in 1960. However, this increase has not been accompanied by the increase of the economic output as well. 


\section{The Model and Main Econometric Issues}

Standard Cobb-Douglas production function with constant returns to scale is usually the starting point.

$$
Y=A K^{\alpha} H^{1-\alpha}
$$

where $Y$ is economic output (measured as the real GDP per capita in international dollars), $K$ and $H$ represent stock of physical and human capital, $A$ captures the total factor productivity. Following Barro and Lee (2010) the econometric model is defined as follows:

$$
\ln y_{i t}=\beta_{0}+\beta_{1} \ln k_{i t}+\beta_{2} S_{i t}+u_{i t}
$$

Where $\beta_{1}$ is the share of the physical capital in the economic output and $\beta_{2}$ represents the marginal rate of return to the human capital. Barro and Lee (2010) use the symbol $S$ to describe the deposit of the human capital as the average years of schooling. As introduced in the first section, in order to test for the most adequate approximation of the human capital not only the years of schooling but also different variables to approximate $S$ (which is in detail described in the next chapters) are used.

Several econometric problems have to be concerned. Frequent problem is the invoked endogenity. To address this issue several approaches are suggested. Topel (1999) suggests constraining the model and setting $\beta$ between 0.35 and 0.5 . Other possibility is to apply instrumental variables or advanced econometric methods (Generalized methods of moments - GMM, General least squares - GLS, Maximum likelihood estimation MLE). This paper follows Cohen and Soto (2007) who build an unconstrained version and apply Blundell and Bond (1998) system GMM estimation with instrumental variables which provide more precise estimates and lower biases than traditional estimators.

In order to eliminate the time independent countries' specifics (fixed effects - denoted by FE) usually first difference (FID) or forward orthogonal deviation (FOD) transformation is used. Hayakawa (2009) shows that the orthogonal deviations method performs better with more consistent results and therefore FOD is reported also in the paper.

In all regression two-step robust GMM estimation is applied and robust standard errors are reported in parenthesis. As the instrumental variables the lags of explanatory variables 4 and 5 periods and first differences of the explanatory variables lagged 4 and 5 periods are used. Reliability of the estimates from the GMM system estimation method is tested by Sargan or Hansen test (the results of the so called overidentifying restrictions are reported below the tables).

\section{Results}

The empirical section covers the main results divided into three parts reflecting the main objectives and three steps to get more plausible estimates of the human capital impact on economic growth. In the first part the econometric model with the average years of schooling using fixed (FE) and random effects (RE) and GMM system estimation is tested. In the second part the quality of the schooling is included and reflects its impact on the estimates. In the third part I apply new proxies of the human capital. 
PART 1 - Human capital as the average years of schooling

First, there are dynamic panel data regressions using the average years of schooling based on Barro and Lee (2010) as the human capital proxy. Main results are reported in the Table 2. Columns (1) and (2) encompass fixed (FE) and random (RE) effects regression as a benchmark - the endogenity problem mentioned above results in lower coefficients of the physical capital. The coefficients for schooling are consistently significant at the $1 \%$ level. Column (3) reports results from the system GMM estimation. All statistics reported in the footnotes confirm the overall reliability of the model and the validity of the instrumental variables.

Table 1 | Average Years of Schooling and Economic Growth

\begin{tabular}{|l|c|c|c|}
\hline & $\begin{array}{c}\text { FE } \\
\text { (1) }\end{array}$ & $\begin{array}{c}\text { RE } \\
\text { (2) }\end{array}$ & $\begin{array}{c}\text { GMM } \\
\text { (3) }\end{array}$ \\
\hline Ink & $0.360^{* * *}$ & $0.418^{* * *}$ & $\begin{array}{c}0.621^{* * *} \\
(0.054)\end{array}$ \\
\hline avg.yrsch & $\begin{array}{c}0.082^{* * *} \\
(0.016)\end{array}$ & $\begin{array}{c}0.064^{* * *} \\
(0.006)\end{array}$ & $\begin{array}{r}0.031 \\
(0.013)\end{array}$ \\
\hline Difference - Hansen test (p) & & & 0.726 \\
\hline Hansen (p-values) & & & 0.489 \\
\hline Sargan (p-values) & & & 0.005 \\
\hline Number of instrumets & & & 30 \\
\hline Arellano - Bond test for AR 2 & & 909 & 0.001 \\
\hline Arrelano - Bond test for AR 3 & 909 & & 909 \\
\hline N & & & \\
\hline
\end{tabular}

Notes: dependent variable Log of economic output, explanatory variables - log of physical capital per capita InK and the average years of schooling, FE -fixed effects, RE - random effects, robust standard errors in parenthesis. * - coefficients are significant at $10 \%$ level, ${ }^{* *} 5 \%,{ }^{* * *} 1 \%$

Source: Barro and Lee (2010), PWT 6.3, own calculations

Once applying the fixed and random effects techniques (reported in column 1 and 2), the results confirm positive effect of schooling on economic growth. The results suggest that, holding other things constant, economic output would increase by around 6-8\% for every additional year of schooling which is close to the results of previous human capital literature (e.g. Soto, 2008). Once applying the GMM system estimation with instrumental variables which should give more adequate picture with unbiased estimates, the coefficient turns out to be statistically insignificant even at the $10 \%$ level. This raises additional doubts about consistency of the average years of schooling variable as a human capital proxy.

PART 2 - Reflecting the quality of the human capital

This part is addressing the other important topic linked with the plausible estimates of the positive human capital influence on economic growth - the quality of the human capital. The need to reflect the quality of the human capital has been described in the introduction. Following the findings of Soto (2008) this part aims to answer how the estimates change when the different quality of schooling across countries is taken into account. The quality 
itself is measured according to the methodology used by Hanushek and Kimko (2000). The way how to measure the quality of the schooling remains in most researches the same - scores of the students in the international testing (most frequently the results from PISA or IALS testing are used).

According to Soto (2008) the countries are divided into three groups reflecting the quality of education - countries with high quality of education (that means countries with students scoring highest in the international tests), medium and low quality of education ${ }^{2}$.

The data are available for 65 countries over the same period 1960-2005. For the testing the same econometric model (IV) is applied only with one difference - the human capital quality is incorporated into the model, i.e. 9 different regression tests reflecting 3 different quality groups and 3 different methods were performed. For each quality category and method the results are displayed in the following table.

\section{Table 2 | Impact of the Years of Schooling with Reflection of the Human Capital Quality}

\begin{tabular}{|l|c|c|c|}
\hline yrsch (high) & $\begin{array}{c}\text { FE } \\
\text { (1) }\end{array}$ & $\begin{array}{c}\text { RE } \\
\text { (2) }\end{array}$ & $\begin{array}{c}\text { GMM } \\
\text { (3) }\end{array}$ \\
\hline yrsch (high) & $\begin{array}{c}0.118^{* * *} \\
(0.017)\end{array}$ & $\begin{array}{c}0.092^{* * *} \\
(0.017)\end{array}$ & $\begin{array}{c}0.064^{*} \\
(0.036)\end{array}$ \\
\hline yrsch (low) & $\begin{array}{c}0.009) \\
(0.010) * * *\end{array}$ & $\begin{array}{c}0.044^{* * *} \\
(0.009)\end{array}$ & $\begin{array}{c}0.056^{* * *} \\
(0.040)\end{array}$ \\
\hline
\end{tabular}

Notes: dependent variable In(Y per capita), explanatory variables - log of physical capital per capita InK and the average years of schooling, FE -fixed effects, RE - random effects, robust standard errors in parenthesis Source: Barro and Lee (2010), Soto (2008), PWT 6.3, own calculations

At first sight it is visible that the high countries with the indicated higher schooling quality (countries with students scoring higher in international testing) report significantly higher estimates of the effect of the years of schooling on economic growth. These results are consistent with the findings of Soto (2008). The comparison with the results in the Table 1 shows that e.g. in the countries with the high quality of education the contribution of the education to economic growth is higher than indicated once using a general average. This again suggests reflecting the impact of different levels of education in the growth models.

Repeatedly there is a statistical lower significance of the estimates when the GMM system estimation is applied. This confirms that when using the average years of schooling as a proxy reflecting the human capital quality may be crucial prerequisite for relevant estimates.

2 The three categories of the countries concerning the quality of schooling are organized as follows: High represents 16 countries with the best results of the students in the international testing and thus the highest quality of schooling is being expected. Soto (2008) builds an index $(0 ; 1)$, where 1 is the country with highest quality of education. In this case in the high category are countries with the index higher than 0.8. Med encompasses 30 countries with index ranging between $0.48-0.8$. Low covers the resting 19 countries with index below 0.48 . 
PART 3 - Different approach to approximate the human capital

As mentioned in the introduction, the average years of schooling as the human capital proxy may be for many reasons considered as the cause for distortion of the relationship between growth and human capital. Thus in this section this estimation is replaced also by the percentage share of population with no formal education, share of population with primary education, secondary education and tertiary education as proxies for the human capital, which can bring not only more reliable results in the regression tests but also additional information what is the specific effect of the given level of education.

Table 3 encompasses output of overall 12 different regression tests where the dependent variable is always the economic growth $(\ln Y)$. Explanatory variables are the $\log$ of physical capital $(\ln K)$ and the share of population with certain level of education used as a proxy of the $S$ variable in the equation IV.

Table 3 | Economic Growth and the Level of Education

\begin{tabular}{|l|c|c|c|}
\hline & $\begin{array}{c}\text { FE } \\
(\mathbf{1})\end{array}$ & $\begin{array}{c}\text { RE } \\
\mathbf{( 2 )}\end{array}$ & $\begin{array}{c}\text { GMM } \\
\text { (3) }\end{array}$ \\
\hline no formal & $\begin{array}{l}-0.004^{*} \\
(0.002)\end{array}$ & $\begin{array}{l}-0.004^{* * *} \\
(0.000)\end{array}$ & $\begin{array}{l}-0.006^{*} \\
(0.003)\end{array}$ \\
\hline primary & $\begin{array}{l}-0.001 \\
(0.001)\end{array}$ & $\begin{array}{c}0.001^{* * *} \\
(0.001)\end{array}$ & $\begin{array}{c}-0.001 \\
(0.001)\end{array}$ \\
\hline secondary & $\begin{array}{c}0.007^{* * *} \\
(0.002)\end{array}$ & $\begin{array}{c}0.007^{* * *} \\
(0.001)\end{array}$ & $\begin{array}{c}0.009^{*} \\
(0.002)\end{array}$ \\
\hline tertiary & $\begin{array}{c}0.017^{* * *} \\
(0.003)\end{array}$ & $\begin{array}{c}0.018^{* * *} \\
(0.002)\end{array}$ & $\begin{array}{c}0.015^{* *} \\
(0.004)\end{array}$ \\
\hline
\end{tabular}

Notes: FE-fixed effects, RE-random effects, robust standard errors in parenthesis

Source: Barro and Lee (2010), PWT 6.3, own calculations

The results offer interesting findings:

1. There is a positive effect of the secondary and tertiary educated population on growth confirmed across the econometric methods. This suggests, that $1 \%$ increase of the share of population with tertiary education can increase the economic growth by about $1.5 \%$.

2. On the other hand, negative effect of the share of population with no formal education has been confirmed. This suggests that high share of uneducated population can hinder the economic growth.

3. On the contrary to results introduced in Part 1 and 2, the estimates are at almost the same level regardless the method is used. Again the estimates, when GMM system estimation is used, are with lower statistical significance. As anticipated this can indicate more plausible and stabile performance of the alternative human capital proxies to the average years of education.

As anticipated the negative link between the share of uneducated population and the economic growth and positive link between well educated population and growth have been confirmed. The breakdown reflecting the separate levels of education in the population can in this way offer interesting findings and suggestions not to focus only on the tertiary level of education. 


\section{Conclusions}

This paper aimed to further investigate the empirical link between the human capital and the economic growth. Using modern econometric techniques, it tried to address the main arguments why the empirical research usually fails to undoubtedly prove the positive effect of the education on economic growth. In the first part, the model with the average years of education was build and showed that the positive impact on growth is consistently confirmed only when fixed and random effects methods are used. Once the GMM system method is applied, the estimates are lower and statistically insignificant even at $10 \%$ level.

The second part of the paper addressed the objection raised by Prichett (2001) that quality of the human capital has to be always concerned in order not to overestimate the effect on economic growth. Results in the Part 2 conclude that when the quality of the human capital is considered in the model the estimates change significantly. In the countries with indicated higher level of the schooling quality there is significantly higher rate of return from the years of schooling. This confirms intuitive assumption that the quality of the schooling really matters. Thus, not only the length of education is important - the higher quality the time spent at school has, the better results of graduates can be expected. In general, in the countries with better schooling the impact of the average years of schooling on economic growth is higher. The schooling quality is particularly important topic in countries with low quality of education where the impact of the average years of schooling is diminishing due to low quality of educational system.

Part 1 and Part 2 repeatedly confirm that the coefficients are statistically less significant or insignificant even at the $10 \%$ level (see Table 1 and 2), when dynamic panel data regression is used - GMM system estimation with instrumental variables, which is acknowledged to give much more adequate and unbiased estimates than when we use fixed or random effects methods. Therefore the Part 3 follows Prichett (2001) and Kruger and Lindhal (2001) and try to approximate the human capital using different variable. The shares of population with no formal, primary, secondary or tertiary level of education as an alternative proxy of the human capital have been applied. The results are consistent across the econometric techniques and the estimates have higher statistical significance. Furthermore, the results are consistent with the earlier evidence of Barro and Lee (2010). Specifically, the paper confirms that there is positive relationship between the share of population with secondary and tertiary level of education and economic growth, i.e. leveraging the share of population with higher education can stimulate the economic upsurge. As anticipated there is also negative link between the share of population with no formal education and economic growth. In other words, the economic growth can be hampered by the high share of the population with no formal education. This formulates the suggestion that the government should accent also the strategy to decrease the share of uneducated population and not only focus on the tertiary class. As the results indicate, far more important than the average years of education for economic growth is the right balance between primary to tertiary educated people in the population as well as the quality of the educational process.

To conclude, the results of this paper suggest approximating the human capital rather with the share of population with certain level of education than the standard average years of education. We should also always bear in mind, that also the quality of the human capital is an important factor affecting the impact on economic growth and should be reflected. 


\section{References}

Barro, R. J., Lee, J. W. (2010), "A New Dataset of Educational Attainment in the World 1950-2010." NBER, Working Paper No. 15902.

Benhabib, J., Spiegel, M. M. (1994), "The Role of Human Capital in Economic Development: Evidence from Aggregate Cross-country Data." Journal of Monetary Economics, Vol. 34, No. 2, pp. 143-73.

Bernanke, B. S., Gurkaynak, R. S. (2001), "Is Growth Exogenous? Taking Mankiw, Romer, and Weil Seriously." NBER Macroeconomics Annual, Vol. 16, pp. 11-57.

Bills, M., Klenow, P. (2000), "Does Schooling Cause Growth?" American Economic Review, Vol. 90, No. 5, pp. 1160-83.

Blundell, R., Bond, S. (1998), "Initial Conditions and Moment Restrictions in Dynamic Panel Data Models." Journal of Econometrics, Vol. 87, No. 1, pp. 115-43.

Caselli, F. (2005), "Accounting for Cross-Country Income Differences." in Aghion, P. and Durlauf, S. (Eds.), Handbook of Economic Growth.

Cohen, D., Soto, M. (2007), “Growth and Human Capital: Good Data, good Results." Journal of Economic Growth, Vol. 12, No. 1, pp. 51-76.

De La Fuente, A., Domenech, R. (2000), "Human Capital in Growth Regressions: How Much Difference Does Data Quality Make?" CEPR. University of Valencia.

Hall, R., Jones, C. (1999), "Why Do Some Countries Produce so much more Output per Worker than Others?" The Quarterly Journal of Economics, Vol. 114, No. 1, pp. 83-116.

Hanushek, E. A., Kimko, D. D. (2000), "Schooling, Labor-Force Quality, and the Growth of Nations." The American Economic Review, Vol. 90, No. 5, pp. 1184-1208.

Hanushek, E. A., Woessmann, L. (2008), "The Role of Cognitive Skills in Economic Development." Journal of Economic Literature, Vol. 46, No. 3, pp. 607-668.

Hayakawa, K. (2009), “First Difference or Forward Orthogonal Deviation - Which Transformation Should Be Used in Dynamic Panel Data Models? A Simulation Study." Economics Bulletin, Vol. 29, No. 3, pp. 2008-2017.

Krueger, A., Lindahl, M. (2001), "Education for Growth: Why and for Whom?" Journal of Economic Literature, Vol. 39, No. 4, pp. 1101-36.

Lucas, R. (1988), "On the Mechanics of Economic Development." Journal of Monetary Economics, Vol. 22, No. 1, pp. 3-42.

Nehru, V., Svanson, E., Dubey, A. (1993), "A New Database on Human Capital Stock." World Bank Working Paper No. 1124.

Nelson, R., Phelps, E. (1966), “Investment in Humans, Technological Diffusion and Economic Growth." American Economic Review Papers and Proceedings, Vol. 61, pp. 69-75.

Pritchett, L. (2001), “Where Has All the Education Gone?" World Bank Economic Review, Vol. 15, No. 3, pp. 367-91.

Romer, P. (1990), “Endogenous Technological Change." Journal of Political Economy, Vol. 98, No. 5, pp. 71-102.

Roodman, D. (2008), "A Note on the Theme of Too Many Instruments, Centre for Global Development." Working Paper No. 125, Washington, DC.

Soto, M. (2002), "Rediscovering Education in Growth Regressions.” OECD Development Centre, Working Paper No. 202. 
Soto, M. (2008), "The Casual Effect of Education on Aggregate Income." Instituto de Analisis Economico. Barcelona.

Temple, J. (2001), "Generalizations that Aren't? Evidence on Education and Growth." European Economic Review, Vol. 45, No. 4-6, pp. 905-18.

Topel, R. (1999), "Labor Markets and Economic Growth." in: Ashenfelter, O., Card, D. (Eds), Handbook of Labor Economics. Elsevier Science, Amsterdam, pp. 2943-84. 